\title{
The Changes of Structure and Wettability of Siloxane Polymers under Vacuum Ultra Violet Action.
}

\author{
V.N. VASILETS, T.I. YURANOVA, A.N. PONOMAREV \\ Institute for Energy Problems of Chemical Physics \\ Chernogolovka, Noginsk dist., Moscow reg., RUSSIA, 142432
}

\begin{abstract}
Changes in wettability and surface structure of siloxane polymers under vacuum ultraviolet (VUV) irradiation (wavelength $147 \mathrm{~nm}$ ) and storage in water were investigated by contact angle measurements and ATR FTIR spectroscopy. The increase of wettability observed after VUV irradiation is associated with the formation of $\mathrm{CO}$ and $\mathrm{OH}$ polar groups in the polymer surface layer. Storage in water and air media of VUV treated samples leads to the increase of contact angle which could be related to dissolution of small highly polar fragments in water or to decomposition of unstable products of photooxidation. Correlation of contact angle changes with the water content in the polymer surface layer observed during storage in water for untreated samples leads to the conclusion that in this case water sorbtion is the major path to wettability changes.
\end{abstract}

\section{Introduction.}

During the last two decades siloxane polymers have become of growing interest for membrane technology, biomedical applications, and microlithography [1,2] because of the high gas permeability, unique mechanical and optical properties, and high durability. However surface characteristics of siloxane polymers such as wettability, adhesion, compatibility with different biological media often need an additional modification. In this study the increase in wettability under VUV irradiation, aging process in water and air media as well as water content of the polymer surface during storage processes has been investigated using ATR FTIR spectroscopy and contact angle measurements.

\section{Experimental methods.}

Samples of siloxane polymers (diameter $10 \mathrm{~mm}$, thickness $1-3 \mathrm{~mm}$ ) were irradiated in vacuum chamber at air pressure 0.1-100 torr, flow rate 20 
$\mathrm{cm}^{3}(\mathrm{STP}) / \mathrm{min}$ and room temperature. The hollow cathode gas discharge resonant Xe lamp KsR-2A [3] equipped with $\mathrm{MgF}_{2}$ window and located at a distance $30 \mathrm{~mm}$ from the polymer surface has been used. The radiation intensity was measured by "sun blind" vacuum photodiod.

Contact angle measurements were carried out by using captive bubble method [4]. Air bubbles with the size not more than $1 \mathrm{~mm}$ were introduced and placed on the underside of polymer sample immersed in water. Contact angles were directly measured by screen projection apparatus.

IR spectra of polymer surface layer were recorded on Perkin- Elmer model 1720X FTIR spectrometer using attenuated total reflection technique ( Harrick ATR attachment, KRS-5 prism, angle $45^{\circ}, 25$ reflections)

The structures of two investigated siloxane polymers are shown below:
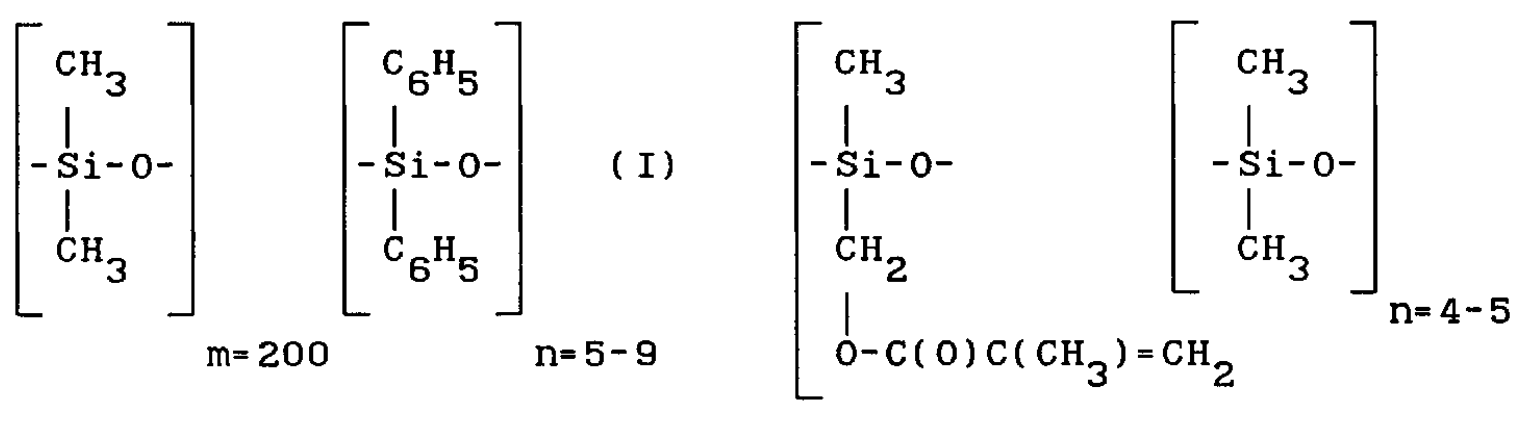

Polymer II in distinction to polymer I has side polar groups and is of special interest for comparative analysis of wettability changes in different conditions.

\section{Results and discussion.}

Fig. 1,2 shows the effects of irradiation time and air pressure on surface contact angle $\theta$ observed immediately following VUV treatment (curve 1, Fig. 1,2 ) and after 24 hours of subsequent storage on air at room temperature (curve 2, Fig.1,2). The contact angle levels off for irradiation times more than 15 min and riches the minimum value after irradiation at a air pressure $\sim 2.5$ torr. The storage on air (humidity 60\%) leads to the increase of minimum $\theta$ value from $11^{\mathrm{O}}$ to $18^{\mathrm{O}}$.

The decrease of contact angle after VUV treatment evidently can be attributed to the formation of polar $\mathrm{OH}$ and $\mathrm{CO}$ groups in photooxidation processes. As it was shown [5] the concentrations of $\mathrm{CO}$ and $\mathrm{OH}$ groups rich a maximum value in our irradiation conditions at the same air pressure 2.5 torr where the minimum contact angle was observed (see Fig. 2). 


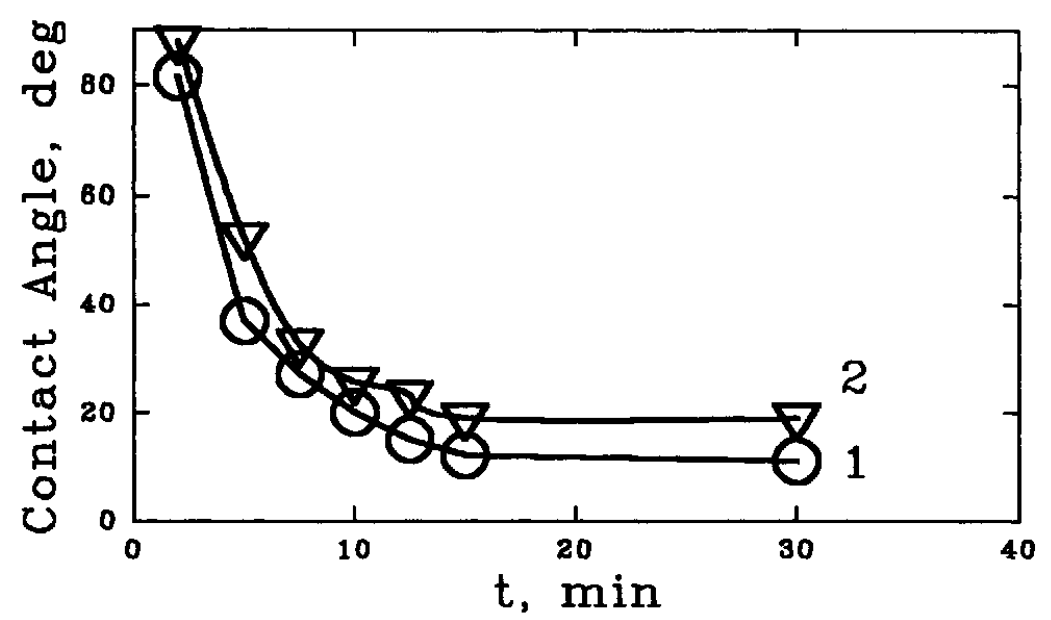

Fig.1 Variation of the contact angle with VUV irradiation time: 1-immediately after treatment(30 min, 2.5 torr), 2-after subsequent storage on air for 24 hours.

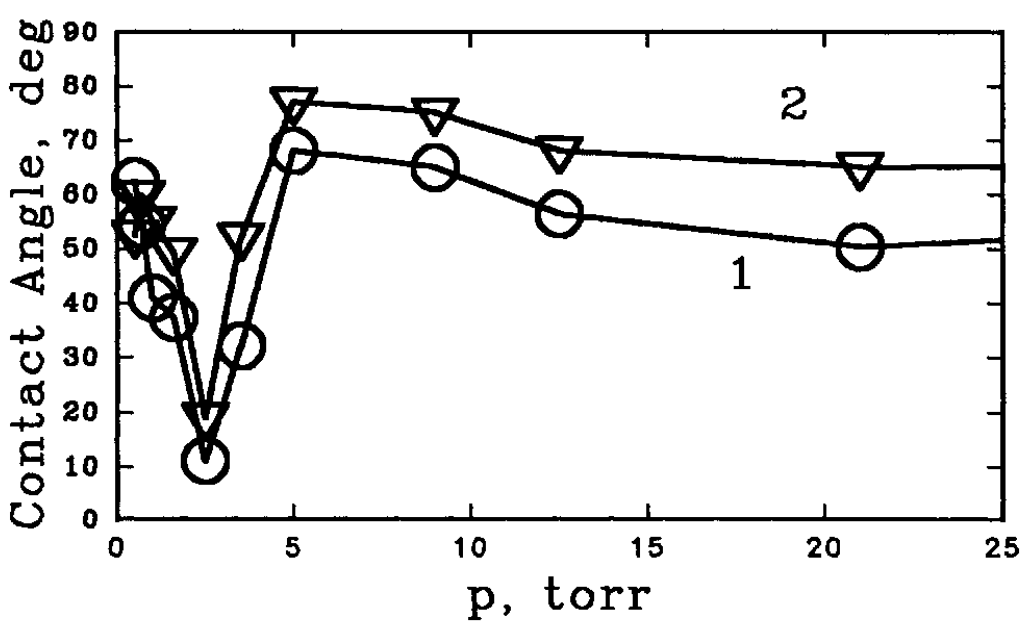

Fig.2 Variation of the contact angle with air pressure: 1-immediately after treatment(30 min, 2.5 torr), 2-after subsequent storage on air for 24 hours.

Fig. 3 presents variations of $\theta$ vs time of contact with water for both untreated and VUV treated samples of polymer II. The $\theta$ value for untreated sample decreases from $68^{\circ}$ to $50^{\circ}$ whereas that of VUV treated sample increase from $10^{\circ}$ to $25^{\circ}$ after 2 days of contact.

Many authors [6-9] attribute the wettability changes observed during storage of polymers in different polar and ion containing media to the orientation of side chain polar groups toward the surface of polymer. However in our case of two siloxane polymers only one ( polymer II) contains side chain polar groups. Nevertheless they both exhibit very similar evolution of contact angle decrease during storage in water. Moreover having initially different 
contact angles

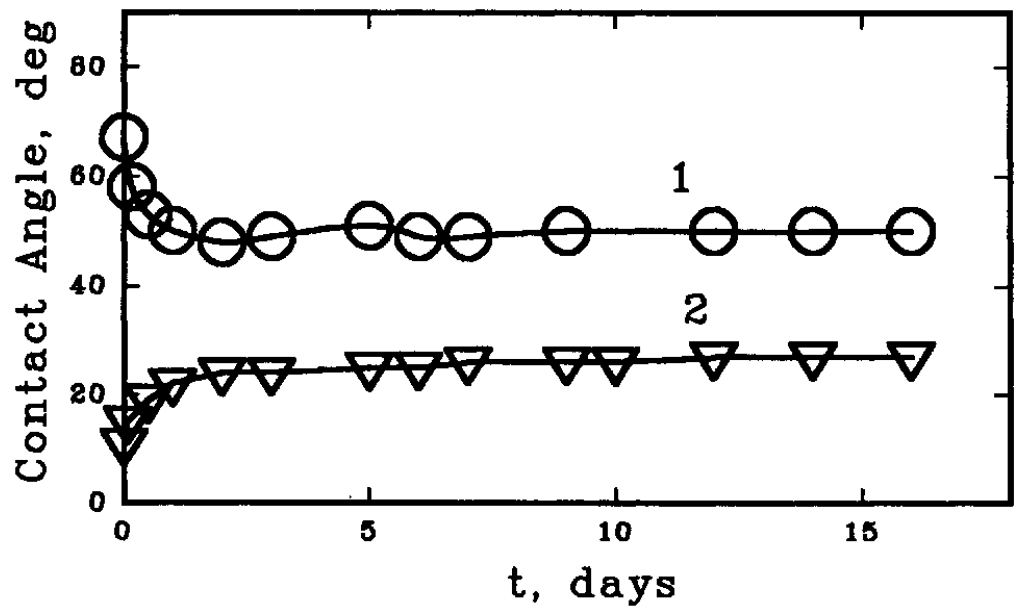

Fig.3 Variation of the contact angle versus time of contact with water for untreated(1) and VUV treated(2) samples of polymer II.

$\left(85^{\circ}\right.$ for polymer I and $68^{\circ}$ for polymer II) they both reach practically the same $\theta$ value about $50^{\circ}$ after storage in water for two days. Notice that polymer I which does not contain side polar groups exhibit more intense decrease of $\theta$ value than polymer II. Therefore the reorientation of polar groups in siloxane polymers play unimportant role in wettability changes caused by contact with water.

The surface composition as a function of contact time with water was also investigated by IR ATR spectroscopy. Fig. 4 shows the ATR FTIR spectra of untreated polymer II at a different times of contact.

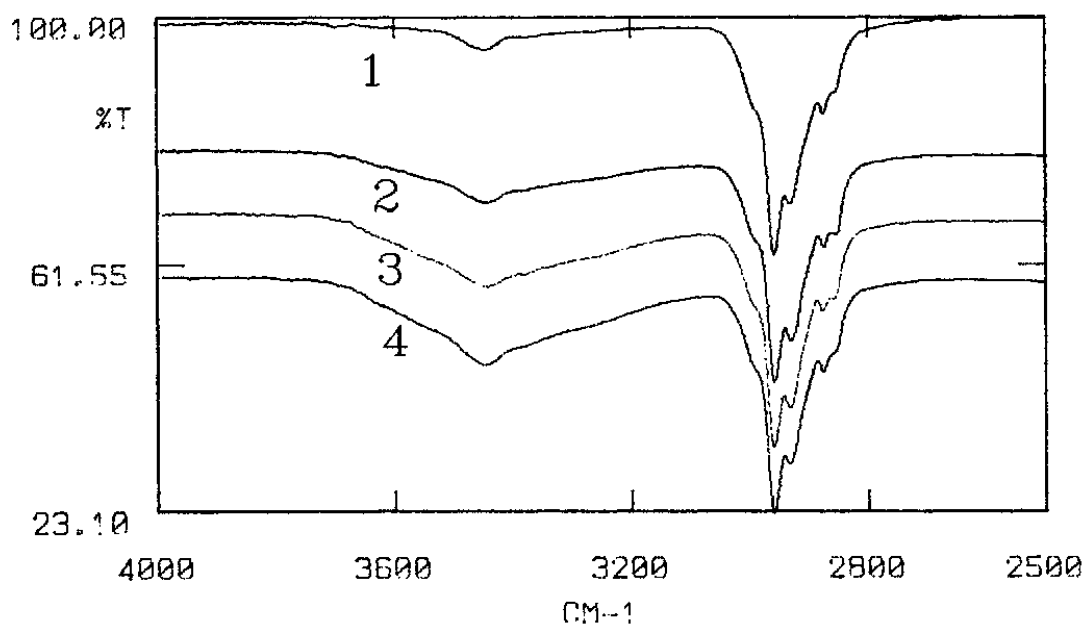

Fig.4 Variation of IR (ATR) spectrum of the polymer II: with time of contact on water at 23C: dry sample(1), $4(2), 24(3)$ and $60(3)$ hours storage in water. 
As it clearly seen the broad band in the region $3200-3600 \mathrm{~cm}^{-1}$ attributed to $\mathrm{OH}$ stretching vibration, almost nonapparent initially, increases considerably. According to [10] this absorption band in IR spectrum can be attributed to the water molecules adsorbed in the surface polymer layer. Fig. 5 presents the variation of both contact angle and optical density $D$ in the region 3200$3600 \mathrm{~cm}^{-1}$ vs time of contact with water. These values are changing very synchronously with the time of storage.

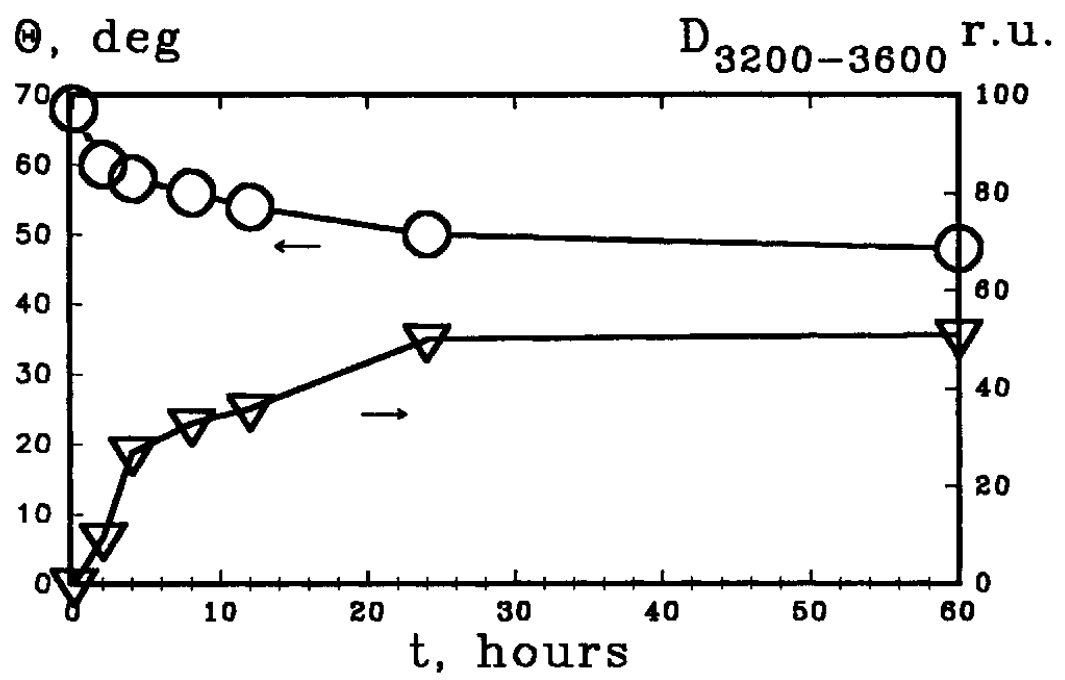

Fig.5 Variation of the contact angle and the concentration of $\mathrm{OH}$ groups versus time of contact with water for the polymer II(untreated sample)

Fast increase of $D$ and decrease of $\theta$ after first 5 hours of contact and following slow approximation of both to the constant value during two days revealed that decrease of contact angle for untreated sample can be explained by the increase of water content in the polymer surface layer. This conclusion is confirmed also by drying experiments when contact angle increased simultaneously with the evaporation of water from the sample. According to the model developed by Adamson [11] the polymer/water system is a type B soft interface which is able to undergo important restructuration resulting in significant changes of the surface energy.

The increase of $\theta$ for VUV treated samples during storage on air probably due to the decay of unstable polar products of photooxidation. As it was shown for plasma treated polyimide films [12] the increase of contact angle in the aging process was followed by the decrease of peroxide radicals concentration. Storage in water of VUV treated samples and subsequent drying at the temperature $60^{\circ} \mathrm{C}$ was found to reduce the intensities of $\mathrm{OH}$ and $\mathrm{CO}$ absorption bands in ATR FTIR spectrum. This suggests that dissolution of low 
molecular polar products of photooxidation may be the reason of wettability decrease observed after the storage in water.

\section{Conclusion.}

VUV irradiation in the presence of air leads to the formation of $\mathrm{CO}$ and $\mathrm{OH}$ groups in the surface layer of siloxane polymers, resulting in an increase of wettability. Under our experimental conditions (wavelength $147 \mathrm{~nm}$, intensity $10^{15}$ quant $/ \mathrm{cm}^{2} \mathrm{~s}$, distance $3 \mathrm{~cm}$ from VUV source) the water contact angle levels off with irradiation time and riches the minimum value under irradiation at air pressure 2.5torr. The storage of treated samples in water or on air media result in the decrease of wettability which could be related to dissolution of small highly polar fragments in water or to decomposition of unstable products of photooxidation like peroxide radicals. The decrease of water contact angle for untreated siloxane polymers during the storage in water was found to be due to the surface restructuration of polymers as a result of water adsorption rather than orientation of side chain polar groups.

\section{References}

1. I.G. Valunin, Z.I. Moroz, G.V. Gjavrishvily, L.S. Chabrova in "Polymers and Biomaterials", Elsevier Science Publishes B.V., (1991)p501.

2. A.E. Arbatskii, A.K. Vakar, A.V. Golubev, E.G. Krasheninnikov, V.V. Liventsov, S.O. Macheret, V.D. Rusanov, A.A. Fridman, High energy chemistry (Rus.), 24(1990)N3p256.

3. S.A. Yakovlev, Optical-mechanical industry (Rus.) (1978)N4p52.

4. A.W. Adamson, Physical Chemistry of Surfaces, 3rd ed.,Wiley, New York, (1976)p115.

5. V.N. Vasilets, A.V. Kovalchuk, A.N. Ponomarev, this volume.

6. D.R. Gagnon, T.J. McCarthy, J. Appl. Polym. Sci., 29(1984)4335.

7. H. Yasuda, A. Skarma, T. Yasuda, J.Polym.Sci., Polym.Phys.Ed., 19(1981)1285.

8. E. Ruckenstein, S.V. Gourisankar, J.Colloid and Interface Sci., 107(1985)N2p488.

9. L. Lavelle, J. Schultz, J. Colloid and Interface Sci., 106(1985)N2p1285.

10 W:A.P. Luck, "Water in polymers", ACS Symposium Series, 127(1980)p43.

11 A.W. Adamson, "Water in polymers", ACS Symposium Series, 127(1980)p87.

12 A.B. Gil'man, R.R. Schifrina, V.K. Potapov, L.S. Tuzov, L.E. Vengerskaya, G.G. Grigor'eva, High energy chemistry (Rus.), 27(1993)N2p79. 